\title{
Effect of number and diameter of follicles on plasma concentrations of inhibin and $\mathrm{FSH}$ in mares
}

\author{
F. X. Donadeu and O. J. Ginther \\ Department of Animal Health and Biomedical Sciences, University of Wisconsin, Madison, \\ WI 53706, USA
}

The role of the number of follicles and circulating immunoreactive inhibin in the decrease in plasma FSH concentrations that occurs during development of a follicular wave was studied in mares. All follicles $\geqslant 6 \mathrm{~mm}$ in diameter were ablated by ultrasound-guided transvaginal aspiration of follicular fluid on day $\mathbf{1 0}$ after ovulation. During the subsequent wave, all follicles, the three largest follicles (three follicle group), the largest follicle (single follicle group) or no follicles were retained and the remaining follicles were ablated before they reached $>10 \mathrm{~mm}$ in diameter $(n=10-11$ mares per group). Ablation of new follicles was continued until the day on which the largest follicle of the new wave reached $25 \mathrm{~mm}$ in diameter (day 18 after ovulation in the 'no follicle' group). Diameters of retained follicles were measured once a day by transrectal ultrasonography. Plasma samples were taken once a day and analysed by radioimmunoassay for concentrations of FSH and immunoreactive inhibin (includes dimeric inhibin as well as free $\alpha$-subunit forms). Data were normalized to the day of the expected start of the decrease in plasma FSH concentrations (day 0: largest follicle $13 \mathrm{~mm}$ in diameter in the follicle-retained groups).

\section{Introduction}

Follicular growth occurs in waves in mares, as in cattle (for review, see Ginther (2000)). The ovulatory wave begins (as determined by ultrasonography) at the middle of the interovulatory interval. Initially, the follicles of a wave grow as a cohort. Thereafter, the largest follicle continues to grow (dominant or ovulatory follicle) while smaller follicles regress (subordinate follicles). The dissociation into a dominant follicle and subordinate follicles is termed follicle deviation and occurs when the largest follicle reaches 22-23 mm in diameter (Gastal et al., 1997, 1999a). The initiation of a follicular wave is associated temporally with a surge in plasma FSH concentrations (Bergfelt and Ginther, 1993). A decrease in the FSH surge begins when the largest follicle of the resulting wave is a mean $13 \mathrm{~mm}$ in diameter (Gastal et al., 1997). The decrease in plasma FSH concen-

Email: donadeu@ahabs.wisc.edu
A simultaneous increase in circulating concentrations of FSH $(P<0.05)$ and immunoreactive inhibin $(P<0.05)$ occurred before the largest follicle reached $13 \mathrm{~mm}$ in diameter, which indicates that immunoreactive inhibin produced by follicles $<13 \mathrm{~mm}$ in diameter did not suppress FSH. Plasma concentrations of FSH decreased $(P<0.05)$ and immunoreactive inhibin concentrations increased $(P<0.05)$ after day 0 in the follicle-retained groups. A slower decrease in FSH concentrations was associated temporally with a delay in the increase in immunoreactive inhibin concentrations in the 'single follicle' group relative to the 'three follicle' and 'all follicle' groups. All follicleretained groups had similar plasma concentrations of $\mathrm{FSH}$ and immunoreactive inhibin after the expected beginning of deviation in growth rates between the two largest follicles (largest follicle $22-23 \mathrm{~mm}$ in diameter). These results indicated that the decrease in plasma FSH concentrations from the start of the decrease until the expected day of deviation was a function of multiple follicles of a wave and was attributable to the secretion of inhibin. Thereafter, the largest follicle alone accounted for the continued $\mathrm{FSH}$ suppression.

trations coincides initially with the growth of all follicles of a wave and continues during growth of the dominant follicle after deviation (Bergfelt and Ginther, 1993). The FSH decrease is necessary for the occurrence of deviation and regression of the subordinate follicles of a wave (Ginther et al., 2000). In cattle, it has been concluded that the growing follicles cause the decrease in circulating FSH concentrations and that multiple follicles of a wave $\geqslant 5 \mathrm{~mm}$ in diameter contribute to the decrease (Gibbons et al., 1997). The relationship between the number of follicles in a wave and the decrease in plasma FSH concentrations has not been studied in mares.

A negative feedback effect of follicles on FSH secretion in mares has been demonstrated by ovariectomy (Freedman et al., 1979a; Driancourt and Palmer, 1984), administration of follicular fluid (Miller et al., 1979, 1981; Bergfelt and Ginther, 1985, 1986), and follicular ablation (Hinrichs et al., 1991; Gastal et al., 1999b). The suppressive effects of follicles on FSH secretion have been attributed to a nonsteroidal, proteinaceous fraction of follicular fluid (Miller et al., 1979) and to oestradiol (Burns and Douglas, 1981; 
Thompson et al., 1983; Wiest et al., 1987). The involvement of oestradiol in the suppression of circulating FSH concentrations in mares has been demonstrated in association with follicle deviation (Gastal et al., 1999a,b). Inhibin is a follicular protein found in different molecular mass forms that include dimeric inhibin (bound $\alpha$ - and $\beta$-subunits) and free $\alpha$-subunit variants (Moore et al., 1994). Studies in cows (Robertson et al., 1986, 1989; Knight et al., 1989) have shown that dimeric inhibin forms, but not free $\alpha$-subunit, suppress FSH secretion. The involvement of inhibin in suppression of $\mathrm{FSH}$ in mares is indicated by the observations that: (i) circulating concentrations of $\mathrm{FSH}$ and immunoreactive inhibin are related reciprocally during the oestrous cycle (Bergfelt et al., 1991; Roser et al., 1994; Nagamine et al., 1998; Nagaoka et al., 1999); and (ii) passive immunization against inhibin results in increased plasma FSH concentrations (Nambo et al., 1998; Briant et al., 2000). These results are similar to those obtained in other species (Mann et al., 1989, 1990; Glencross et al., 1994; Kaneko et al., 1995, 1997; Arai et al., 1996).

Studies have shown that immunization against inhibin increases the number of preovulatory follicles and ovulations in mares (McCue et al., 1992; McKinnon et al., 1992; Nambo et al., 1998). However, the temporal relationships among changes in circulating concentrations of inhibin, concentrations of FSH and growth of the follicles of a wave have not been elucidated in mares.

The aims of the present study in mares were: (i) to characterize the involvement of different numbers of growing follicles $>10 \mathrm{~mm}$ in diameter in the decrease in plasma $\mathrm{FSH}$ concentrations associated with a follicular wave; and (ii) to evaluate the role of follicular inhibin in the decrease in FSH concentrations. All follicles $\geqslant 6 \mathrm{~mm}$ in diameter were ablated at mid-cycle and specific numbers of follicles (none, one, three or all) of the following wave were retained. The temporal relationships between follicular growth and circulating concentrations of FSH and immunoreactive inhibin were then examined. The following hypotheses were tested: (i) that the decrease in plasma FSH concentrations would be a function of the number of follicles retained in a wave; and (ii) that within each follicle group, changes in circulating concentrations of FSH would have a temporal, inverse relationship to changes in immunoreactive inhibin concentrations.

\section{Materials and Methods}

\section{Experimental animals}

Non-lactating Pony mares $(n=42)$ of mixed breeding, aged 3-15 years, body weight 230-460 kg, were used from March to August in the northern hemisphere. The mares were kept outdoors and had been exposed to artificial lights (15 h per day) during the previous winter. The mares were fed alfalfa and grass hay and had free access to water and mineralized salt. Before the experiment, ovulations were synchronized by administration of $10 \mathrm{mg}$ dinoprost i.m. (Lutalyse; Pharmacia and Upjohn Co, Kalamazoo, MI; Ginther, 1992) to all mares. Follicles $>30 \mathrm{~mm}$ in diameter were monitored once a day by ultrasonography to establish the day of ovulation. Mares double-ovulating in the previous cycle or with apparent uterine pathology (fluid collections; Ginther, 1995) before the start of the experiment were not used.

\section{Follicle ablation}

Ablation of specified follicles was performed by ultrasound-guided transvaginal aspiration of follicular contents as described by Gastal et al. (1997). Follicles that refilled with fluid and grew to $10 \mathrm{~mm}$ in diameter were reablated. All follicles $\geqslant 6 \mathrm{~mm}$ in diameter were ablated on day 10 after ovulation in all mares to eliminate follicles from previous waves and to facilitate tracking of individual follicles of the subsequent or new wave. The mares were then assigned randomly to four groups. When a follicle of the new wave first reached $10 \mathrm{~mm}$ in diameter, various numbers of follicles $6-10 \mathrm{~mm}$ in diameter were ablated so that no follicles ('no follicle' group, $n=11$ ), the largest follicle ('single follicle' group, $n=10$ ), the three largest follicles ('three follicle' group, $n=10$ ) or all follicles ('all follicle' group, $n=10$ ) were retained. Follicles of the same diameter were chosen randomly for retention. When a new follicle $10 \mathrm{~mm}$ in diameter was detected during subsequent daily examinations, all follicles $\geqslant 6 \mathrm{~mm}$ were ablated, except for the designated retained follicles. Periodic ablations were continued until the largest follicle reached $25 \mathrm{~mm}$ in diameter in the follicle-retained groups or on day 18 after ovulation in the no follicle group (expected day the largest follicle would have reached $25 \mathrm{~mm}$ in diameter; Gastal et al., 1997). Animals with fewer than three follicles $\geqslant 6 \mathrm{~mm}$ in diameter when the first $10 \mathrm{~mm}$ follicle of the new wave was detected were not used, so that all mares would have an equal chance to be included in any of the four groups.

\section{Data collection}

Ovaries were monitored once a day with an ultrasound scanner equipped with a $5 \mathrm{MHz}$ linear-array transducer (Aloka SSD-500V; Aloka, Wallingford, CT), starting on day 8 after ovulation and extending until the next ovulation. At each scanning session, the diameter of follicles $>5 \mathrm{~mm}$ in diameter was estimated by comparison with the graduation marks on the scanner screen. After the follicles reached 10 $\mathrm{mm}$ in diameter, the four largest follicles or the designated retained follicles were tracked from examination to examination and measured with electronic callipers (Ginther, 1995). Follicles were measured by taking the mean width and length from a frozen image. After the follicles reached $15 \mathrm{~mm}$ in diameter, two frozen images were used.

Blood samples were taken every day from day 8 after ovulation until the next ovulation. Samples were taken 
via jugular venepuncture into heparinized tubes and immediately centrifuged at $1500 \mathrm{~g}$ for $6 \mathrm{~min}$. The plasma fraction was separated and stored at $-20^{\circ} \mathrm{C}$ until hormone assays were performed.

\section{Hormone assays}

Plasma FSH concentrations were measured by a double antibody radioimmunoassay validated previously for mares by Freedman et al. (1979b). Intra- and interassay coefficients of variation, determined from a pool of plasma containing 1.7-3.4 ng FSH ml ${ }^{-1}$, and sensitivity ( $n=8$ assays) were $14.05 \%, 7.13 \%$ and $0.44 \mathrm{ng} \mathrm{FSH} \mathrm{ml}^{-1}$, respectively. For $\mathrm{FSH}$, as well as for immunoreactive inhibin, assay sensitivity was calculated by subtracting two SD from the mean maximum percentage binding and the value obtained was averaged over all assays.

Concentrations of immunoreactive inhibin in plasma were measured by a radioimmunoassay kit (Institute of Reproduction and Development, Monash Medical Center, Clayton, Victoria). The kit included inhibin as a $32 \mathrm{kDa}$ fraction of bovine follicular fluid for iodination and antiinhibin (Pool B, 1989) generated against a 31 kDa fraction of bovine follicular fluid. The crossreactivity of this assay in mares has been described by Roser et al. (1994); the antibody recognizes all dimeric inhibin forms, as well as full-length $\alpha$-subunit and pro- $\alpha C$ forms. Assay procedures were similar to those described by Roser et al. (1994), except that iodination was done using lodogen (Matteri et al., 1987) and a different reference standard was used (recombinant 32 kDa bovine inhibin; IP-1095; Peninsula Laboratories Europe Ltd, St Helens). Assay of serial dilutions of the standard (5-250 ng ml-1) and two different pools of plasma from oestrous and dioestrous mares (5-100 $\mu \mathrm{l}$ each) in total volumes of $100 \mu \mathrm{l}$ resulted in displacement curves that were similar. Intra- and interassay coefficients of variation, calculated from a pool of plasma containing 27.1-37.5 ng ml $\mathrm{m}^{-1}$, were 10.5 and $2.9 \%$, respectively, and the sensitivity was $7 \mathrm{ng} \mathrm{ml}^{-1}$ ( $n=6$ assays).

\section{Statistical analyses}

Previous data from our laboratory (Gastal et al., 1997) indicated that the plasma FSH decrease associated with the development of a follicular wave began when the largest follicle reached a mean of $13 \mathrm{~mm}$ in diameter. Therefore, follicular and hormonal data were normalized to the day on which the largest follicle of the new wave reached $13 \mathrm{~mm}$ in diameter (day 0). Data from the 'no follicle' group were normalized to the mean day on which the largest follicle reached $13 \mathrm{~mm}$ in diameter in the other three groups (mean, day 15 after ovulation). Follicular and hormonal data were also normalized to the day of ablation of all follicles $\geqslant 6 \mathrm{~mm}$ in diameter (day 10 after ovulation). In each instance, the longest interval of time for which data from all mares were available was used in the statistical analyses; data were truncated to the day on which the first mare ovulated.
In contrast to circulating immunoreactive inhibin, FSH data did not follow a normal distribution, as assessed by a Kolmogorov-Smirnov test (level of significance, $P<0.05$ ); therefore, FSH data were log-transformed. Thereafter, for each hormone, extreme values were tested using the extreme standardized deviate (Pearson and Hartley, 1976). Under these criteria, two distinctly high values for immunoreactive inhibin from different mares were excluded from the statistical analyses. Hormonal and follicular data were then analysed by the SAS MIXED procedure taking the animal (group) as the random effect and using a first order autoregressive structure to account for the autocorrelation among samples taken over time. Main effects of group and day and the interaction of group by day were determined. When the group effect or the interaction were significant, Duncan's multiple range test was used to detect differences among individual means. Single-point measurements for follicular end points were analysed by one-way ANOVA. The level of significance was $P<0.05$.

\section{Results}

Twelve mares were removed from the experiment and replaced for the following reasons: follicles were ablated mistakenly or left unablated in eight mares; two mares developed an apparent minor wave (Ginther and Bergfelt, 1992); follicles of one mare did not grow to $10 \mathrm{~mm}$ in diameter by week 2 of the experiment; and one mare had a dominant follicle that grew at a very low rate $(1.25 \mathrm{~mm}$ day $\left.^{-1}\right)$. The interovulatory interval of the latter mare was exceptionally long (34 days) which, among the follicleretained groups, was found to be an outlier by the method of the extreme standardized deviate (Pearson and Hartley, 1976). Data from two mares that had double ovulations were included in the statistical analyses.

There were no differences among groups before the establishment of the experimental groups (largest follicle of the new wave reaches $10 \mathrm{~mm}$ in diameter) in the following follicular characteristics: (i) number of follicles $\geqslant 6 \mathrm{~mm}$ in diameter on day 10 after ovulation (combined mean: $11.1 \pm 0.9$ follicles); (ii) diameter of the largest follicle on day 10 after ovulation $(16.1 \pm 0.7 \mathrm{~mm})$; (iii) day of detection of the first $10 \mathrm{~mm}$ follicle of the new wave (3.4 \pm 0.2 days); and (iv) number of follicles $\geqslant 6 \mathrm{~mm}$ in diameter when the largest follicle of the new wave reached $10 \mathrm{~mm}$ in diameter $(4.9 \pm 0.3$ follicles). A mean $5.4 \pm 0.6$ follicles grew to $>10 \mathrm{~mm}$ in diameter in the 'all follicle' group from the time of ablation of all follicles on day 10 after ovulation until the largest follicle of the new wave reached $25 \mathrm{~mm}$ in diameter. There were no differences in maximum diameter $(38.5 \pm 0.9 \mathrm{~mm})$ or growth rate $\left(3.0 \pm 0.1 \mathrm{~mm} \mathrm{day}^{-1}\right)$ of the dominant follicle among the follicle-retained groups. All mares ovulated from the dominant follicle of the post-ablation wave, and the interovulatory interval was longer $(P<0.01)$ in the 'no follicle' group $(29.7 \pm 1.3$ days $)$ than in the groups with follicles retained ( $24.2 \pm 0.3$ days). 
Averaged over all groups, plasma concentrations of FSH increased after the ablation of all follicles $\geqslant 6 \mathrm{~mm}$ in diameter on day 10 after ovulation (Fig. 1). Plasma immunoreactive inhibin concentrations decreased initially after ablation, followed by an increase after day 2 after ablation (day 12 after ovulation).

Diameter of the largest follicle and concentrations of plasma FSH and immunoreactive inhibin, normalized to the day on which the largest follicle reached $13 \mathrm{~mm}$ in diameter (day 0), are shown (Fig. 2). The diameter of the largest follicle was similar among the groups with follicles retained. Exceptionally high circulating FSH concentrations in a single mare on day -1 accounted for the high mean concentrations in the 'all follicle' group on that day. Plasma FSH concentrations were lower continuously in each of the follicle-retained groups than in the 'no follicle' group beginning on day 1 . Plasma FSH concentrations were higher in the 'single follicle' group than in the 'three follicle' or 'all follicle' groups on day 2. Thereafter, no significant differences in $\mathrm{FSH}$ concentrations were detected among the follicle-retained groups. Compared with the 'no follicle' group, plasma immunoreactive inhibin concentrations were higher by day 1 in the 'three follicle' and 'all follicle' groups, and by day 3 in the 'single follicle' group. Immunoreactive inhibin concentrations in the 'single follicle' group were lower on day 2 than in the 'three follicle' and 'all follicle' groups. There were no significant differences in plasma immunoreactive inhibin concentrations among the follicle-retained groups starting on day 3.

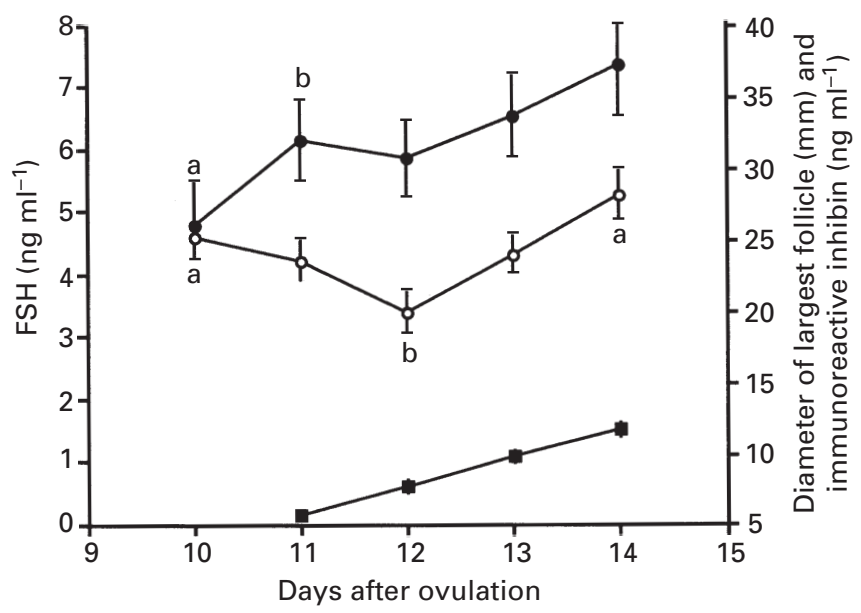

Fig. 1. Concentrations of FSH $(\bullet)$ and immunoreactive inhibin $(\bigcirc)$ in plasma, and diameter of the largest follicle (ם) after ablation of all follicles $\geqslant 6 \mathrm{~mm}$ in diameter on day 10 after ovulation. Values were averaged over all groups ( $n=41$ mares) and are presented as mean \pm SEM. Day effect was significant for FSH $(P<0.0005)$, inhibin $(P<0.001)$ and diameter of the largest follicle $(P<0.001)$. abFor FSH and immunoreactive inhibin, means with different letters are significantly different $(P<0.05)$.
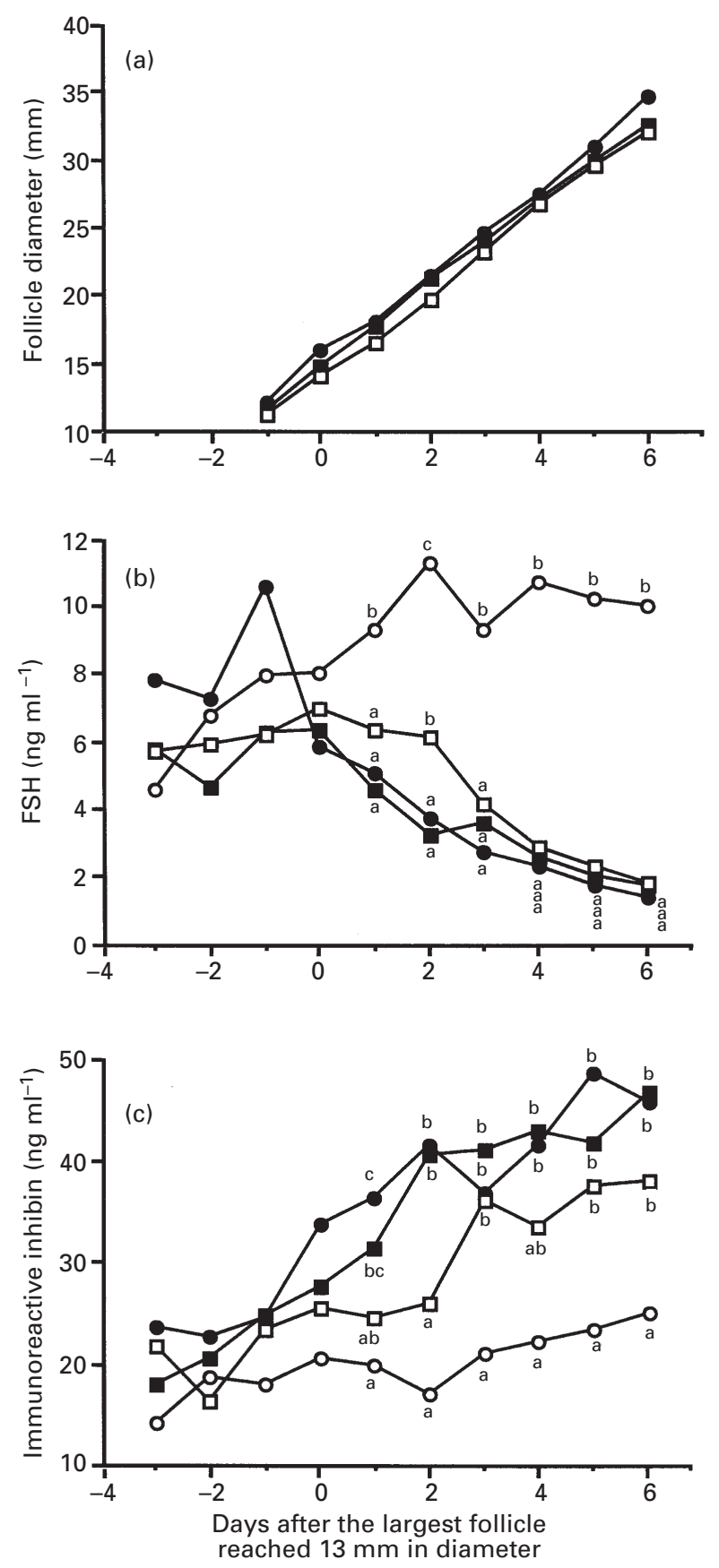

Fig. 2. Mean (a) diameter of the largest follicle and plasma concentrations of (b) FSH and (c) immunoreactive inhibin normalized to the day on which the largest follicle of the new wave reached $13 \mathrm{~mm}$ in diameter (day 0 ) in mares with no follicles $(\bigcirc)$, one follicle $(\square)$, three follicles $(\boldsymbol{\square})$ or all follicles $(\boldsymbol{)})$ of the wave retained $(n=10-11$ mares per group). Data in the 'no follicle' group were normalized to the mean day on which the largest follicle reached $13 \mathrm{~mm}$ in diameter in the other three groups (day 15 after ovulation). Overall SEMS for each end point were as follows: largest follicle: 0.9; FSH: 0.9; and immunoreactive inhibin: 3.5 . There was an effect of day $(P<0.0001)$ for diameter of the largest follicle. There were effects of day $(P<0.0001)$, group $(P<0.0005)$ and group $\times$ day $(P<0.001)$ for $\mathrm{FSH}$ and immunoreactive inhibin. abcFor each end point, group means within a day with different letters are significantly different $(P<0.05)$. 


\section{Discussion}

Follicular aspiration of the dominant follicle (Dippert et al., 1995), the preovulatory follicle (Hinrichs et al., 1991) and all follicles > $5 \mathrm{~mm}$ (Gastal et al., 1997, 1999a,b) or > $8 \mathrm{~mm}$ (Duchamp et al., 1995) in diameter by a transvaginal ultrasound-guided technique has been used previously for research purposes in mares. In the present study, maximal diameter and growth rate of the dominant follicle, and duration of the interovulatory interval in the follicleretained groups were similar to those reported previously for intact Ponies and after periodic follicle ablations to retain only the two largest follicles of a wave (Gastal et al., 1997, 1999a). The proportion of double ovulations (two of 41) was similar to results reported in Ponies by Ginther (1992). The consistent hormonal responses detected after follicular ablation among groups in the present study and in other studies (Hinrichs et al., 1991; Gastal et al., 1999b) indicate that this technique is effective in functionally ablating follicles. Clinical side effects after the repeated use of the procedure were not observed in this or in previous studies (Bracher et al., 1993; Gastal et al., 1997). Averaged over the follicle-retained groups, the plasma FSH decrease started when the largest follicle of the new wave was a mean $13.7 \pm 0.6 \mathrm{~mm}$ in diameter, in agreement with the results of Gastal et al. (1997). Thus, normalization of data in this experiment to the day on which the largest follicle reached $13 \mathrm{~mm}$ in diameter was justified for comparing the effects of number of follicles on the decrease in FSH concentrations and to study the involvement of circulating inhibin in the decrease.

Examination of the follicular and hormonal changes before the largest follicle reached $13 \mathrm{~mm}$ in diameter indicated that ablation of all follicles $\geqslant 6 \mathrm{~mm}$ in diameter on day 10 after ovulation caused an immediate increase in plasma FSH concentrations and a concomitant but transient (during days 1 and 2 after ablation) decrease in immunoreactive inhibin concentrations. The 2 day transient decrease in plasma immunoreactive inhibin concentrations may have reflected the ablation of inhibin-producing follicles, but this could not be assessed critically. An increase in circulating immunoreactive inhibin occurred during days 2-4 after ablation concomitant with a continued increase in $\mathrm{FSH}$ concentrations. This result indicates that the increasing plasma inhibin concentrations did not have an FSHsuppressing effect while the follicles of the new wave were growing from means of $7.7 \mathrm{~mm}$ to $11.6 \mathrm{~mm}$ in diameter. Free inhibin $\alpha$-subunit forms, which have no FSH-suppressing activity (Knight et al., 1989; Robertson et al., 1989), as well as dimeric inhibins, are measured by the radioimmunaossay that was used in the present study. The previous finding agrees with two to five times higher circulating $\mathrm{FSH}$ concentrations (days 2-6) in the 'no follicle' group, in which follicles were ablated before they exceeded $10 \mathrm{~mm}$ in diameter, than in the follicle-retained groups; this difference in plasma FSH concentrations is similar to that reported during the breeding season between ovariectomized and intact mares (Freedman et al., 1979a). The conclusion that follicles $<13 \mathrm{~mm}$ in diameter secrete inhibin forms that do not suppress plasma FSH concentrations is consistent with reports that granulosa cells of follicles $<10 \mathrm{~mm}$ in diameter contain inhibin $\alpha$-subunits (Nagamine et al., 1998; Goudet et al., 1999), but not $\beta$-subunits (Nagamine et al., 1998). Two free inhibin $\alpha$-subunit variants have been isolated from equine follicular fluid (Moore et al., 1994). Circulating immunoreactive inhibin with no FSH-suppressing activity has also been detected in mares during the second half of pregnancy (Nambo et al., 1997).

The capacity for FSH suppression by growing follicles began when the follicles reached approximately $13 \mathrm{~mm}$ in diameter (day 0), as indicated by the onset of the decrease in plasma FSH concentrations. The results supported the two hypotheses on the relationships among number of follicles, a decrease in circulating FSH concentrations and an increase in inhibin concentrations. The plasma immunoreactive inhibin concentrations increased and the FSH concentrations decreased more rapidly in the 'three follicle' and 'all follicle' groups than in the 'one follicle' group, as indicated by significant differences on day 2 . The changes in concentrations of the two hormones were similar between the 'three follicle' and 'all follicle' groups. This result indicated that three follicles were adequate for inhibin production and suppression of plasma FSH. It was not determined whether two follicles would be similarly effective. In cattle, more than two follicles of a wave were involved in the initial decrease in plasma FSH concentrations (Gibbons et al., 1997).

During the initial FSH decrease (days 1 and 2), inhibin alone may have accounted for the FSH suppression. An increase from baseline circulating concentrations of oestradiol, the other known FSH-suppressant in mares, was not detected at this time in the same group of Pony mares (Gastal et al., 1999a,b), or at the equivalent time in cattle (Gibbons et al., 1999). Therefore, plasma oestradiol concentrations probably did not play a role in the initial FSH decrease. The role of follicular inhibin in the initial decrease in plasma FSH concentrations is consistent with the reported suppression of circulating FSH concentrations by a proteinaceous fraction of follicular fluid in ovariectomized mares (Miller et al., 1979) and the increase of circulating FSH concentrations after treatment with inhibin antiserum in mares during dioestrus (Nambo et al., 1998).

The mean diameter of the largest follicle on day 3 $(23.9 \mathrm{~mm})$ in the follicle-retained groups was close to the diameter reported by Gastal et al. $(1997,1999 a)$ at the start of follicle deviation $(22-23 \mathrm{~mm})$. That is, a change from suppression of plasma $\mathrm{FSH}$ by multiple follicles to suppression by a single follicle occurred at the approximate expected start of deviation on day 3. Earlier reports in mares (Gastal et al., 1999b) and cattle (Ginther et al., 2000) indicated that the largest follicle alone is responsible for the continued decrease in circulating FSH concentrations after the start of deviation. This conclusion is supported in the present study by the suppression of FSH concentrations to a 
similar extent in all of the follicle-retained groups, starting on day 3. Plasma immunoreactive inhibin concentrations remained increased in the 'three follicle' and 'all follicle' groups starting on day 2 and in the 'single follicle' group starting on day 3 and extending until the end of the experiment (day 6). However, the relative role of inhibin in the FSH decrease after deviation was not studied in this or previous experiments. Briant et al. (2000) indicated that an antiserum against inhibin after the largest follicle reached $20 \mathrm{~mm}$ in diameter increased plasma FSH concentrations. Although not focused on deviation, this reported finding is consistent with a continuing suppressing effect of inhibin on FSH after the expected start of deviation. Although the temporal relationship between an increase in circulating oestradiol and the beginning of deviation is well established (Gastal et al., 1999a,b), the relative role of plasma oestradiol in the FSH decrease after deviation has not been determined. Miller et al. (1979) investigated a proteinaceous fraction of follicular fluid in ovariectomized mares and reported that circulating inhibin and oestradiol may have a synergistic effect on FSH suppression. A combined action of circulating inhibin and oestradiol in suppressing FSH has been demonstrated in other species, such as cattle (Kaneko et al., 1995), sheep (Mann et al., 1992) and rats (Arai et al., 1996).

This is thought to be the first report in which the changes in follicle development and circulating concentrations of both immunoreactive inhibin and FSH in relation to developing follicular waves in mares have been characterized. On the basis of the temporal relationships among circulating concentrations of $\mathrm{FSH}$, circulating concentrations of immunoreactive inhibin and number of retained follicles, it is concluded that the growing follicles of a wave acquire the ability to secrete inhibin with FSH-suppressing activity when they reach approximately $13 \mathrm{~mm}$ in diameter. The secretion of FSH-suppressing inhibin by multiple follicles of a wave induces the decrease in plasma FSH concentrations from its beginning (when the largest follicle is $13 \mathrm{~mm}$ in diameter) until the expected time of deviation; inhibin secretion by the three largest follicles is sufficient to induce the FSH decrease. After the expected time of deviation, the largest follicle appears to be solely responsible for continued suppression of plasma FSH concentrations. The relative roles of inhibin and other follicular factors, such as oestradiol, in the suppression of circulating FSH concentrations during and after deviation are not known.

The authors thank E. L. Gastal for technical assistance, D. R. Bergfelt for advice with hormone assays, the Pharmacia Company for the gift of Lutalyse and the National Hormone Pituitary Program for the hFSH antibody. This work was supported by the University of Wisconsin, Madison, WI and the Eutherian Foundation, Cross Plains, WI.

\section{References}

Arai K, Watanabe G, Taya K and Sasamoto S (1996) Roles of inhibin and estradiol in the regulation of follicle-stimulating hormone and luteinizing hormone secretion during the estrous cycle of the rat Biology of Reproduction 55 127-133

Bergfelt DR and Ginther OJ (1985) Delayed follicular development and ovulation following inhibition of FSH with equine follicular fluid in the mare Theriogenology 24 99-108

Bergfelt DR and Ginther OJ (1986) Follicular populations following inhibition of follicle stimulating hormone with equine follicular fluid during early pregnancy in the mare Theriogenology 26 733-747

Bergfelt DR and Ginther OJ (1993) Relationship between FSH surges and follicular waves during the estrous cycle in mares Theriogenology 39 781-796

Bergfelt DR, Mann BG, Schwartz NB and Ginther OJ (1991) Circulating concentrations of immunoreactive inhibin and FSH during the estrous cycle of mares Journal of Equine Veterinary Science 11 319-322

Bracher V, Parlevliet J, Fazeli AR, Pieterse MC, Vos PLAM, Dieleman SJ, Taverne MAM and Colenbrander B (1993) Repeated transvaginal ultrasound-guided follicle aspiration in the mare Equine Veterinary Journal Supplement 15 75-78

Briant C, Blanc M, Daels P and Guillaume D (2000) Effect of passive and specific immunization against inhibin in pony mares Theriogenology $\mathbf{5 3}$ 493 (Abstract)

Burns PJ and Douglas RH (1981) Effects of daily administration of estradiol$17 \beta$ on follicular growth, ovulation, and plasma hormones in mares Biology of Reproduction 24 1026-1031

Dippert KD, Ray BS and Squires EL (1995) Aspiration of the dominant follicles in mares and its effect on subsequent follicular development Animal Reproduction Science $\mathbf{4 0}$ 77-88

Driancourt MA and Palmer E (1984) Time of ovarian follicular recruitment in cyclic pony mares Theriogenology 21 591-600

Duchamp G, Bezard J and Palmer E (1995) Oocyte yield and the consequences of puncture of all follicles larger than 8 millimeters in mares Biology of Reproduction Monograph Series $1233-241$

Freedman LJ, Garcia MC and Ginther OJ (1979a) Influence of ovaries and photoperiod on reproductive function in mares Journal of Reproduction and Fertility Supplement 27 79-86

Freedman LJ, Garcia MC and Ginther OJ (1979b) Influence of photoperiod and ovaries on seasonal reproductive activity in mares Biology of Reproduction 20 567-574

Gastal EL, Gastal MO, Bergfelt DR and Ginther OJ (1997) Role of diameter differences among follicles in selection of a future dominant follicle in mares Biology of Reproduction 57 1320-1327

Gastal EL, Gastal MO, Wiltbank MC and Ginther OJ (1999a) Follicle deviation and intrafollicular and systemic estradiol concentrations in mares Biology of Reproduction 61 31-39

Gastal EL, Gastal MO and Ginther OJ (1999b) Experimental assumption of dominance by a smaller follicle and associated hormonal changes in mares Biology of Reproduction 61 724-730

Gibbons JR, Wiltbank MC and Ginther OJ (1997) Functional interrelationships between follicles greater than $4 \mathrm{~mm}$ and the follicle-stimulating hormone surge in heifers Biology of Reproduction 57 1066-1073

Gibbons JR, Wiltbank MC and Ginther OJ (1999) Relationship between follicular development and the decline in the follicle-stimulating hormone surge in heifers Biology of Reproduction $6072-77$

Ginther OJ (1992) Reproductive Biology of the Mare: Basic and Applied Aspects p. 218, 284-286. Equiservices Publishing, Cross Plains, WI

Ginther OJ (1995) Ultrasonic Imaging and Animal Reproduction: Book 2 (pp 114-117), Book 1 (pp 94-95). Equiservices Publishing, Cross Plains, WI

Ginther OJ (2000) Selection of the dominant follicle in cattle and horses Animal Reproduction Science 60-61 61-79

Ginther OJ and Bergfelt DR (1992) Association between FSH concentrations and major and minor follicular waves in pregnant mares Theriogenology 38 807-821

Ginther OJ, Bergfelt DR, Kulick LJ and Kot K (2000) Selection of the dominant follicle in cattle: role of two-way functional coupling between follicle-stimulating hormone and the follicles Biology of Reproduction 62 920-927

Glencross RG, Bleach EC, Wood SC and Knight PC (1994) Active immunization of heifers against inhibin: effects on plasma concentrations 
of gonadotropins, steroids and ovarian follicular dynamics during prostaglandin-synchronized cycles Journal of Reproduction and Fertility 100 599-605

Goudet G, Belin F, Bezard J and Gerard N (1999) Intrafollicular content of luteinizing hormone receptor, $\alpha$-inhibin, and aromatase in relation to follicular growth, estrous cycle stage, and oocyte competence for in vitro maturation in the mare Biology of Reproduction 60 1120-1127

Hinrichs K, Rand WM and Palmer E (1991) Effect of aspiration of the preovulatory follicle on luteinization, corpus luteum function, and peripheral plasma gonadotropin concentrations in the mare Biology of Reproduction 44 292-298

Kaneko H, Nakanishi Y, Akagi S, Arai K, Taya K, Watanabe G, Sasamoto S and Hasegawa Y (1995) Immunoneutralization of inhibin and estradiol during the follicular phase of the estrous cycle in cows Biology of Reproduction 53 931-939

Kaneko H, Taya K, Watanabe G, Noguchi J, Kikuchi K, Shimada A and Hasegawa $\mathbf{Y}$ (1997) Inhibin is involved in the suppression of FSH secretion in the growth phase of the dominant follicle during the early luteal phase in cows Domestic Animal Endocrinology 14 263-271

Knight PG, Beard AJ, Wrathall JHM and Castillo RJ (1989) Evidence that the bovine ovary secretes large amounts of monomeric inhibin alpha subunit and its isolation from bovine follicular fluid Journal of Molecular Endocrinology 2 189-200

McCue PM, Carney NJ, Hughes JP, Rivier J, Vale W and Lasley BL (1992) Ovulation and embryo recovery rates following immunization of mares against an inhibin alpha-subunit fragment Theriogenology 38 823-831

McKinnon AO, Brown RW, Pashen RL, Greenwood PE and Vasey JR (1992) Increased ovulation rates in mares after immunisation against recombinant bovine inhibin $\alpha$-subunit Equine Veterinary Journal 24 $144-146$

Mann GE, Campbell BK, McNeilly AS and Baird DT (1989) Passively immunizing ewes against inhibin during the luteal phase of the oestrus cycle raises the plasma concentrations of FSH Journal of Endocrinology 123 383-391

Mann GE, Campbell BK, McNeilly AS and Baird DT (1990) Effects of passively immunizing ewes against inhibin and oestradiol during the follicular phase of the oestrous cycle Journal of Endocrinology 125 417-424

Mann GE, Campbell BK, McNeilly AS and Baird DT (1992) The role of inhibin and oestradiol in the control of FSH secretion in the sheep Journal of Endocrinology 133 381-391

Matteri RL, Roser JF, Baldwin DM, Lipovetshy V and Papkoff H (1987) Characterization of a monoclonal antibody which detects luteinizing hormone from diverse mammalian species Domestic Animal Endocrinology 4 157-165

Miller KF, Wesson JA and Ginther OJ (1979) Changes in concentrations of circulating gonadotropins following administration of equine follicular fluid to ovariectomized mares Biology of Reproduction 21 867-872

Miller KF, Wesson JA and Ginther OJ (1981) Interaction of estradiol and a nonsteroidal follicular fluid substance in the regulation of gonadotropin secretion in the mare Biology of Reproduction 24 354-358

Moore KH, Dunbar BS, Bousfield GR and Ward DN (1994) Initial characterization of equine inhibin Biology of Reproduction 51 63-71

Nagamine N, Nambo Y, Nagata $S$ et al. (1998) Inhibin secretion in the mare: localization of inhibin $\alpha, \beta_{A}$, and $\beta_{B}$ subunits in the ovary Biology of Reproduction 59 1392-1398

Nagaoka K, Nambo Y, Nagamine $\mathbf{N}$ et al. (1999) A selective increase in circulating inhibin and inhibin pro- $\alpha \mathrm{C}$ at the time of ovulation in the mare American Journal of Physiology 277 E870-E875

Nambo Y, Nagata S, Oikawa M, Yoshihara T, Tsunoda N, Kohsaka T, Taniyama H, Watanabe G and Taya K (1997) High concentrations of immunorreactive inhibin in the plasma of mares and fetal gonads during the second half of pregnancy Reproduction, Fertility and Development 8 $1137-1145$

Nambo Y, Kaneko H, Nagata S, Oikawa M, Yoshihara T, Nagamine N, Watanabe G and Taya K (1998) Effect of passive immunization against inhibin on FSH secretion, folliculogenesis and ovulation rate during the follicular phase of the estrous cycle in mares Theriogenology 50 545-557

Pearson ES and Hartley HO (1976) Biometrika tables for Statisticians, Vol. 1 pp 42-43. Biometrika Trust, London

Robertson DM, De Vos FL, Foulds LM, McLachlan RI, Burger HG, Hearn MTW, Morgan FJ and de Krester DM (1986) Isolation of $31 \mathrm{kDa}$ form of inhibin from bovine follicular fluid Molecular and Cellular Endocrinology 44 271-277

Robertson DM, Giacometti M, Foulds LM, Lahnstein J, Goss NH, Hearn TW and de Krester DM (1989) Isolation of inhibin $\alpha$-subunit precursor proteins from bovine follicular fluid Endocrinology 125 2141-2149

Roser JF, McCue PM and Hoye E (1994) Inhibin activity in the mare and stallion Domestic Animal Endocrinology 11 87-100

Thompson DL, Jr, Reville-Moroz SI, Derrick DJ and Walker MP (1983) Effects of testosterone, dihydrotestosterone and estradiol on gonadotropin release after gonadotropin releasing hormone administration in cyclic mares Biology of Reproduction 29 970-976

Wiest JJ, Thompson DL, Jr, McNeill-Wiest DR and Garza F, Jr (1987) Effects of dihydrotestosterone administration with and without estradiol pretreatment on gonadotropin secretion in ovariectomized pony mares Domestic Animal Endocrinology 4 167-174

Received 10 November 2000.

First decision 22 January 2001.

Accepted 13 February 2001. 